\title{
DISPUTANDO LO POLÍTICO. LA IZQUIERDA Y LA PRENSA POLÍTICA DE MASAS EN CHILE, 1950-1989
}

\author{
Disputing the political. The Left and the Mass Policy Press in Chile, 1950-
} 1989

\section{RESUMEN}

El siguiente artículo analiza la producción periodística de la izquierda entre 1950 y 1989, para dar cuenta de los procesos de transformación de las prácticas políticas que inciden en la opinión pública. Desde 1950 hasta 1973 los partidos de izquierda produjeron diarios y revistas para disputar el espacio político a través de diversas estrategias periodísticas. A partir de 1977 la izquierda recuperó distintas estrategias periodísticas previas a 1973, cambiando formatos y contenidos en sus publicaciones, expresando sus propias tensiones y reformulaciones para delimitar el campo de lo político, en un período donde la relegitimación de la política era clave en la definición de la futura democracia.

Palabras claves: Prensa, Izquierda, Campo político, Estrategias Periodísticas, Chile.

\section{UNIVERSUM}

Revista de Humanidades y Ciencias Sociales

\author{
CRISTINA MOYANO

\section{BARAHONA} \\ Doctora en Historia, académica \\ del Departamento de Historia de la \\ Universidad de Santiago de Chile, \\ Chile \\ Correo electrónico: \\ cristina.moyano@usach.cl \\ ORCID: 0000-0002-4517-2688 \\ ResearchGate: \\ Scholar.google: \\ Academia.edu:
}

\section{CARLA RIVERA}

ARAVENA

Magister en Estudios Culturales Latinoamericanos, académica del Departamento de Historia de la Universidad de Santiago de Chile, Chile.

Correo electrónico: carla.rivera@usach.cl

ORCID: 0000-0003-2147-3889 ResearchGate: Carla_Rivera_Aravena Scholar.google: Academia.edu: CarlaRivera

Agradecemos el financiamiento otorgado por Dicyt-Universidad de Santiago de Chile, Proyecto Posdoc.031552MB y Convenio USA 1555 VRIDEI 


\begin{abstract}
The following article analyzes the journalistic production of the left between 1950 and 1989, to give an account of the processes of transformation of political practices that affect public opinion. From 1950 until 1973, leftwing parties produced newspapers and magazines in an attempt to dispute the political domain using different journalistic strategies. From 1977, the political left regained different journalistic strategies that had been used prior to 1973, changing formats and contents in their publications, expressing their own tensions and reformulations to delineate the domain of the political, during a period where the re-legitimation of politics was key to defining Chile's future democracy.
\end{abstract}

Keywords: Press, Left-wing, Political Field, Journalistic Strategies, Chile.

Sumario: Introducción. El Sistema Nacional de Prensa. Prensa Política de masas. La (re)significación de una tradición. Prensa de oposición y estrategias periodísticas para la revalidación de la política (1977-1989). Legitimar la política y construir un sentido común democrático. Conclusión.

\title{
INTRODUCCIÓN
}

Este artículo tiene como propósito analizar las acciones que desarrolló la izquierda chilena como parte de sus estrategias para definir el campo de lo político a partir de su incorporación al sistema de comunicación de masas. Entre 1950 y 1989, los partidos de izquierda consolidaron su participación en el espacio público a través de la producción de diarios y revistas con el fin de incidir en la opinión pública. La disputa por la realidad social, la obligó a reformular el sentido de sus publicaciones escritas en función del modelo hegemónico: un sistema nacional de prensa moderna y empresarial. 
En este escenario, caracterizado por las tensiones entre la producción simbólica, intereses políticos declarados y transformaciones mundiales en la industria mediática, analizamos el recorrido de los diarios y revistas políticas de masas para pesquisar cómo la izquierda decidió incidir en la res pública, redefiniendo lo político y la política, desde el campo de la escritura periodística. Cada publicación contó con sus propias estrategias periodísticas que la dotaron de corporeidad y existencia material, una síntesis de las tensiones y consensos políticos que se ajustan a las necesidades de su contexto.

Como señalan distintos autores (Tuchman, 1983; Casero, 2004), el sistema de prensa resulta ser un campo heterónomo donde se entrecruzan y desarrollan luchas internas por la imposición de un principio dominante, visión y división, inclusión y exclusión, a partir de la aprobación de categorías legítimas de construcción del mundo social. En este proceso se juega una definición de mundo que es en sí mismo un acto de movilización que tiende a confirmar o transformar las relaciones de poder (Bourdieu, 2005: 33). Se presentan como centros de poder determinantes en la formación de opinión pública $\mathrm{y}$, consecuentemente, para el tipo de presiones ejercidas por esa opinión pública sobre los centros de decisión del poder. De esta manera, la prensa — al igual que el resto de los medios de comunicación— no son simples intermediarios que operan de manera transparente entre un acontecimiento y el público, por el contrario, ellos construyen un relato en función a sus propios intereses, en donde confluyen distintas estrategias periodísticas, que hacen que el medio pueda influenciar o determinar conductas, modos de pensar y opinar en la sociedad. A partir del estudio de las estrategias periodísticas, es decir, de las definiciones y acciones que ubican a un medio dentro del contexto socio-cultural, que le dan una identidad, una función en el escenario de las comunicaciones y una situación dentro del mercado de la información, podemos revisitar la relación entre prensa, política y poder (Santa Cruz, 2014: $4)$.

Si bien las dimensiones que contempla toda estrategia están relacionadas entre sí y con la sociedad que las enmarca, en las interacciones $\mathrm{y}$ determinaciones tensas o fluidas, una tiende a subordinar a las otras, 
constituyendo el elemento medular desde el cual emerge el perfil del medio. De esta forma, todo medio se ve obligado de manera más o menos sistemática a tomar opciones concretas y cotidianas. Lo fundamental es que junto con tratarse de decisiones muchas veces claves para la propia supervivencia del medio, ellas se toman en el terreno de la práctica y la producción, más que en el de la reflexión, discusión teórica o académica. Esto es lo que conduce a que se produzcan cambios en los estilos, formatos y contenidos, así como también en la articulación entre los intereses económicos y la instalación cultural del medio. Por ello, cuando el medio tiene por objetivo la difusión de una perspectiva ideológico-cultural tiende a la subordinación de los elementos comerciales, mientras que cuando el medio tiene un objetivo informativo y de entretención, lo comercial se vuelve más relevante que el contenido. Sin embargo, las relaciones entre las dimensiones suelen ser más complejas y se transforman en el tiempo.

Los estudio de prensa tienden a homologar a todos los dispositivos periodísticos, olvidando que cada medio define su objetivo - lugar desde donde se levanta su identidad - dentro del sistema de comunicación de masas, atenuando el protagonismo que tienen como actores sociales y políticos en un contexto sociocultural específico, que "involucra poderes, actores, fuerzas políticas y en la producción y puesta en circulación de temas y argumentos destinados a intervenir en el debate político y cultural" (Kircher, 2005: 116). Una mirada que - como señala Antoine Faure - impide complejizar los análisis de la acción política del medio, y por tanto, no da cuenta de su dinámica interna (2017: 75).

\section{EL SISTEMA NACIONAL DE PRENSA}

Las transformaciones socioculturales producto del proceso de modernización que experimentaba el país a inicios de la década de 1920, generaron nuevas demandas hacia otros tipos de información, marcando un desplazamiento en aquellos temas considerados nacionales. La renovación de la prensa modificó las estructuras periodísticas y sentó las bases para la 
formación del público moderno de masas (Rinke, 2002; Santa Cruz y Ossandon, 2005). Se desarrollaron empresas con múltiples servicios específicos con el fin de producir utilidades y se incorporaron nuevas técnicas, formatos y narrativas que buscaban acceder a un mercado en crecimiento, cada vez más segmentado, impactando de lleno en el desarrollo del campo como en las representaciones sociales que se iban erigiendo. De esta forma la mercantilización de los medios de producción se observó

a través de prácticas hoy consideradas clásicas: la separación entre opinión e información, la selección de los hechos y su producción bajo la forma de notas informativas, la impersonalidad del texto con el anonimato de los autores y la intrusión de los anuncios comerciales (Faure, 2015: 75).

Las políticas de protección industrial que se implementaron después de la crisis del 29, consolidaron el modelo liberal del mercado informativo, situando a la publicidad como el mecanismo de obtención de recursos para la subsistencia e iniciando un proceso de acelerada capitalización de la prensa, que se tradujo en el nacimiento de los oligopolios periodísticos reunidos en la Asociación Nacional de la Prensa (1951). Desde 1951 hasta 1973, el campo periodístico quedó sujeto a grandes grupos económicos como El MercurioLord Cochrane, la Sociedad Periodística del Sur (SOPESUR), el grupo ZigZag y el Consorcio Periodístico de Chile S.A. (COPESA).

Este proceso fue resultado de la existencia de "barreras tecnológicas, financieras y organizativas" (Portales, 1981: 113) que incidieron en el desarrollo de un mercado comunicacional desigual, donde la concentración de los mismos se hizo inevitable, la información devino en uno de los numerosos productos comerciales elaborados y administrados por pocos grupos, guiados por la oferta y la demanda, en el cual se cruzaban intereses nacionales e internacionales (Mattelart, 1970). Para 1969 diez grupos controlaban la mayoría de los medios de comunicación nacionales, el 34,3\% de todas las sociedades anónimas chilenas y el 78,4\% del capital. Pero el creciente control de las empresas periodísticas no significó el fin de aquellas publicaciones que mantenían una autonomía de los grandes grupos económicos, asegurando un 
pluralismo ideológico relativo en el mercado comunicacional. Estos diarios y revistas representaron el $14 \%$ de los medios que circularon a nivel nacional, con tirajes poco significativos en relación a los grandes grupos editoriales ${ }^{1}$. Su participación en el sistema de información fue transformándose gracias a la vinculación de los movimientos populares con los partidos de izquierda y alianzas políticas que sostuvieron al Estado de Compromiso, desplazando a la prensa sectorial del sistema de comunicaciones dominante (Riquelme, 1986; Sunkel, 2009); a las políticas de control sobre la libertad de prensa diseñada por el Estado (Contardo, 1985) y al propio desarrollo técnico de la prensa. Todos estos factores incidieron en el sistema que rigió hasta 1973.

A pesar de ello, la tesis del bajo impacto ha marcado la interpretación histórica sobre la prensa del período, como forma de dar cuenta de la falta de pluralismo del mercado informativo, reduciendo la complejidad inherente de los sistemas de comunicación. Si bien el tiraje es un índice aproximado del número de lectores que consume el medio, esto no señala cuántos efectivamente lo leen —un impreso puede tener más de un lector-, ni el impacto que la información expuesta puede ocasionar. De hecho, los impresos ajenos a los conglomerados, la mayoría de ellos vinculados a partidos políticos de izquierda, circularon a través del sistema de venta pública, organizaciones sociales y gremiales, entre otros, construyendo redes de divulgación que nutrieron tanto al sistema de comunicación de masas como al de los sectores populares. Su influencia no puede ser menor si consideramos que en más de una ocasión se vieron expuestos a cierres, censuras y persecuciones por parte de los gobiernos de turno y del resto de los medios de comunicación ${ }^{2}$.

1 Solo en tiraje, los diarios de los conglomerados rondaban las 333 mil unidades día frente los 30 mil del órgano del Partido Comunista El Siglo, 17 mil de las Noticias de Última Hora, y los 120 mil de El Clarín.

2 Entre 1958 y 1970 se hicieron 8 denuncias de censuras a contenidos, llegando incluso a la suspensión de números completos como fue el caso de las revistas Desfile y Punto Final en 1968. 


\section{PRENSA POLÍTICA DE MASAS. LA (RE)SIGNIFICACIÓN DE UNA TRADICIÓN}

Desde mediados de la década del 30, las transformaciones políticas y culturales que se expresaron en la estatización de las demandas populares y de los partidos políticos, sentaron las bases para el nacimiento de una nueva prensa política en manos de los sectores de centro-izquierda, que vieron en esta una forma de participar e incidir en el debate político, socializando posturas para generar alianzas con un público más amplio y diverso que el de los militantes. Como señala Santa Cruz, son propuestas comunicacionales que "se efectúan desde dentro del sistema y no desde fuera y en contra, como había sido lo sustancial del discurso de la prensa obrera" (2014: 26), manteniendo su función propagandística, pues su fin último — además de informar - era la acción política. En este contexto surgieron el diario La Hora (1931-1951) del Partido Radical (PR), el diario Frente Popular (1936-1940) del Partido Comunista (PC) que fue reemplazado más tarde por El Siglo (1940- a la fecha), y Las Noticias de Última Hora (1943-1973) vinculado a militantes del Partido Socialista (PS).

A su vez, la prensa de izquierda incluyó revistas pensadas para diversos públicos, dinamizando el sistema. A diferencia de los diarios que buscan incidir en la acción pública inmediata, las revistas "procesan saberes especializados, conformaciones de ideas, de afectividades, de creencias que operan como mecanismos de integración a espacios sociales específicos" (Munizaga, 1984: 3). Entre los distintos tipos de revistas que circularon por el espacio público, predominaron las que tradujeron debates y socializaron pedagógicamente conceptos e ideas políticas, por sobre otras que podemos considerar de masas: formatos divididos por temas de actualidad, culturales, deportivos, etc., pero cuya construcción discursiva siempre se alineó con una matriz teórica-ideológica explícita.

Los diarios de masas asociados a partidos políticos de izquierda pertenecieron mayoritariamente al PC, cuya cultura política de fuerte 
obrerismo ilustrado marcó el desarrollo de un sistema de comunicación política caracterizado por el peso de la cultura letrada, que se tradujo en la impresión de una diversidad de dispositivos de prensa, asociada a la importancia que tenía el acceso a la información en la ampliación de los horizontes culturales del pueblo y por cierto, en la introducción de los conceptos y lenguajes que permitían dotar de significado a la experiencia social (Álvarez, 2011).

Si bien entre 1953 y 1958 se expresa un estancamiento en la impresión de publicaciones producto de la entrada en vigencia de la Ley de Defensa Permanente de la Democracia (1948 -1958), ${ }^{3}$ el PC generó las condiciones a partir de la creación de sociedades como la Empresa Periodística Horizonte y Talleres Gráficos Lautaro (Imprenta Pacífico), que le permitieron mantener su presencia en el espacio público y, a su vez, producir utilidades gracias a la prestación de servicios de impresión a otras publicaciones de izquierda como al diario Última Hora.

El diario El Siglo, órgano oficial del PC, volvió a circular, luego de la proscripción del partido el 25 de octubre de 1952 con un tiraje que fluctuó entre los 25.000 y 30.000 ejemplares diarios. Pese a la situación política en que se encontraba, circuló de manera más o menos intermitente hasta el 11 septiembre de 1973. Mientras que entre 1940 y 1948 se publicaron 2.742 números (en un total de 2.751 días), entre 1952 y 1973 se imprimieron 7.531 números (en un total de 7.627 días). Desde 1958, el diario tendió a aumentar el número de páginas y a mejorar su factura. A este diario se sumó la revista semanal Vistazo (1952-1965) con 25.000 ejemplares, Nuestro Tiempo con un promedio de 6.000 ejemplares y la revista cultural semanal Pro-Arte con 5.000 ejemplares.

A diferencia del PC, el PS no desarrolló una política comunicacional de masas tan relevante. Su cultura política predominantemente fraccional impactó en la posibilidad de tener un órgano partidario. Marcó presencia a través de la participación de militantes en publicaciones colectivas como

3 Ley que proscribió al Partido Comunista y lo puso en la ilegalidad, por promover actividades de agitación que ponían en riesgo la estabilidad democrática. 
fue el caso del diario Última Hora con un promedio de 30.000 ejemplares, donde compartieron espacio con otros intelectuales y periodistas de izquierda. Esta situación se replicó en la revista Punto Final (1965-1973), publicación quincenal de temas de actualidad creada por el mirista Manuel Cabieses y el socialista Augusto Olivares y Chile Hoy (1972 -1973), de la editorial estatal Quimantú, cuya directora fue la socialista Marta Harnecker. Por otro lado, la prensa partidaria interna se organizó a través de la editorial Prensa Latinoamericana, que publicó diversos boletines y folletos de circulación militante (Drake, 1992:Garrido, 2017).

A partir del año 1957, con el nacimiento de la Democracia Cristiana (DC), la variedad de diarios asociados a partidos políticos se complejiza (Riquelme, 1984: 21). La redefinición de la democracia en la época implicó que distintos sectores políticos se posicionaron en relación al sentido de las comunicaciones, y, por ende, de la prensa. Por lo que no es extraño el aumento de inversiones en emisoras y publicaciones escritas. La DC creó $L a$ Libertad (1958-60), La Tarde (1965-1970) y La Prensa (1970-1973), diario de oposición a la Unidad Popular (UP).

Entre 1966 y 1971 se evidencia una gran diferencia a favor del PC, años en el que la crítica al gobierno de Eduardo Frei Montalva y la difusión de las propuestas de la UP se volvieron objetivos estratégicos de la comunicación en dicho partido. El PC comenzó a experimentar con el género de diarios sensacionalistas para interpelar a un público masivo. Un ejemplo de ello es el diario La Denuncia (1958), en el que confluye información política con noticias de deportes y crónica roja, no obstante publicó solo nueve números. El éxito fue para el diario Puro Chile (1970-1973), tabloide que combinó información política con noticias deportivas, crónica roja y fotos de mujeres semidesnudas.

Cabe constatar, que los partidos Movimiento de Izquierda Revolucionario (MIR) y Movimiento de Acción Popular (MAPU), que surgen entre 1965 y 1969, no generaron diarios de masas.

En lo que respecta a las revistas, hay un predominio del PC. De 41 publicaciones que circularon entre 1953 y 1973, el PC produjo el 69\% de ellas, 
frente al 26\% del PS. A diferencia del resto de los partidos, los comunistas diseñaron una oferta de publicaciones diversificada. Unas apelaban al lector en tanto "hombre público", interesado en la actualidad con secciones específicas sobre temas políticos, económicos, culturales, tanto nacionales como internacionales como Vistazo (678 números entre 1952 y 1965) y Enfoque Internacional (79 números entre 1967 y 1973). Otras, en cambio, interpelaron al lector en tanto "ente privado", ofreciendo "conocimientos para mantenerse informados sobre cómo realizar una serie de prácticas cotidianas, cómo entretenerse adecuadamente o cómo acceder, aunque sea ficticiamente, al mundo de los "importantes"' (Munizaga, 1984: 5), fueron los casos de Miranda (51 números entre 1959 y 1961) —destinada al público femenino-, las revistas juveniles Gente Joven (50 números entre 1959 y 1961) y Ramona (1971-1973). Entre las culturales destacan Pro-Arte (181 números entre 1948 y 1956), Aurora (24 números entre 1954 y 1968), Ultramar (11 números entre 1959 y 1960) y Nuestra América (20 números entre 1951 y 1953).

Durante la década del 60 aparecen nuevas revistas en función de la reconfiguración del escenario político: la revista de actualidad Desfile (19651968) de la DC y Punto Final (1965-1973) asociada a miristas y socialistas. Esta última se caracterizó por su vinculación con la teoría del foquismo guerrillero y los lineamientos de Regis Debray. Abordó diversos temas políticos de actualidad de un modo confrontacional, en línea con la polarización política del período y la disputa del campo de lo político.

Con el triunfo de Salvador Allende en las elecciones de septiembre de 1970, las publicaciones de izquierda asumieron un rol protagónico en el proceso de formación del "nuevo hombre". A los medios escritos existentes se sumaron las publicaciones que desarrolló la editorial estatal Quimantú. ${ }^{4}$ El objetivo de dicha editorial era crear y difundir un proyecto cultural acorde a las necesidades del momento" (Bergot, 2005). Pese a sus esfuerzos para transformar la cultura lectora del pueblo, entre los que se encuentran el

4 Tras la quiebra de la editorial Zig- Zag, el gobierno de la UP decidió adquirirla y transformarla en una empresa estatal. Dirigida Jorge Arrate, la editorial se transformó en una empresa modelo de gestión, pues fue administrada por ejecutivos y empleados. 
desarrollo de una política de distribución través de sindicatos, oficinas de bienestar social, quioscos y federaciones de estudiantes no logró alcanzar el impacto propuesto.

Los resultados de la encuesta de la Oficina Gubernamental de Informaciones y Radiodifusiones (OIR) fueron categóricos al señalar que la prensa de izquierda provocaba poco interés en los lectores (Rivera, 2015: 345). La organización declaró que de los tres millones de chilenos que habitualmente leían periódicos, sus preferencias se dividían entre cinco diarios de izquierda y seis de oposición. Todas estas publicaciones vendían un total de 853 mil ejemplares, cada uno leído por 3 o 4 personas, de los cuales solo uno se informaba a través de la prensa de izquierda. ${ }^{5}$ La evaluación gubernamental dejaba en evidencia la poca incidencia que tenía la prensa de izquierda en sus lectores y manifestaba la debilidad de las políticas culturales del gobierno de la UP.

La incursión de la prensa política de masas en espacios culturales y juveniles, adaptándose a los derroteros de la industria, con estrategias periodísticas que combinaron lo comercial con lo ideológico, demostró que la izquierda había iniciado un proceso de disputa pública por los sentidos comunes y los actores que participaban de su definición, lo que quedó inconcluso con el Golpe de Estado. De esa manera, los debates sobre las comunicaciones y su rol en la construcción de proyectos políticos revolucionarios hegemónicos quedaron apenas enunciados, sin lograr resolver las tensiones entre estrategias periodísticas que permitieran la autogestión comercial de los medios, ampliación de lectores, conceptos interpretativos de la teoría marxista y la definición de los contornos del campo de lo político.

5 ¿Qué leen los chilenos?, Chile Hoy 1, 4 (7-13 de julio 1972): 9, citado en Rivera, Carla (2017). "Prensa y Política. El Poder de la Construcción de la Realidad. Chile, siglo XIX-XX", 231. 


\section{PRENSA DE OPOSICIÓN Y ESTRATEGIAS PERIODÍSTICAS PARA LA REVALIDACIÓN DE LA POLÍTICA (1977-1989)}

El Golpe de Estado clausuró los espacios públicos para la actividad política amparado por el Bando $\mathrm{N}^{\mathrm{o}}$ 15, el que estableció:

(...) La Junta de Gobierno, desea mantener informada a la opinión pública sobre acontecimientos nacionales. De acuerdo a lo dispuesto en los bandos hasta ahora emitidos y por encontrarse el país en 'estado de sitio', se ha dispuesto ejercer sobre los medios de publicación una estricta censura de prensa (...)

como una primera medida precautoria, durante el día 12 de septiembre de 1973, se ha autorizado solamente la emisión de los siguientes diarios: El Mercurio y La Tercera de la Hora. ${ }^{6}$

A ello se sumó, en 1974, la creación de la Dirección de Comunicación Social (DINACOS), la que tenía como prioridad emitir la información oficial de gobierno y colaborar en el cambio de mentalidad en la población (Donoso, 2013: 109) a través de la supervisión de las ediciones, publicación y distribución, proceso que culminó con la creación de una oficina de censura a cargo del Ministerio del Interior, que a partir de 1980 exigía a todas las editoriales enviar copias de sus ediciones para ser revisadas, aprobadas o censuradas. La junta militar participó de un concepto de objetividad que no permitió discrepancia/discusión: las cosas son lo que son, incrementando el poder de la realidad y consolidando la realidad del poder (Lechner, 2006: 269).

La demonización de la política por parte de la dictadura, impactó notoriamente en la capacidad de la oposición para disputar los órdenes deseados. La única actividad política tolerada por el régimen fue la que emergió en los Centros Académicos Independientes, que en formatos institucionales, con predominio del lenguaje experto y con circulación restringida, entregó los primeros soportes para las discusiones más fundamentales que cruzaban a los intelectuales de izquierda y del centro demócrata cristiano (Moyano, 2009).

Uno de los debates que circuló en estos espacios refirió precisamente

6 Bando $\mathrm{N}^{\mathrm{o}}$ 15, 11 de septiembre de 1973. 
al estudio de las comunicaciones, la prensa y los medios, tanto en torno a la importancia que tenían en la política institucional, como en la capacidad de generar autonomía en los sujetos populares. Centros Académicos Independientes y ONG como CENECA, ECO, ILET, CIDE, PIIE y FLACSO, articularon una red transnacional donde el debate intelectual tomó corporeidad y nutrió las iniciativas editoriales para la disputa política del espacio público (Moyano, 2016).

Para los partidos de izquierda y el centro demócrata cristiano la comunicación de masas y la recurrencia a la prensa, en especial las revistas políticas, fue un factor de fortalecimiento de la esfera política y pública, idea que no se modificó sustancialmente con el Golpe de Estado, siendo objeto de debate y lucha para conseguir instalarse en el espacio público.

Las reflexiones que emergieron en las Universidades en proceso de reforma a fines de los años 60 , sobre las prácticas sociales de la comunicación y hegemonía (Rivera, 2015) fueron claves para repensar la prensa de oposición en los años de la dictadura militar. La importancia que recobró el pensamiento gramsciano, permitió poner especial atención a la necesidad de construir medios de comunicación que fueran capaces de participar de la elaboración de sentidos comunes por los cuales se sustentaran los cambios políticos deseados. No se trataba de recuperar la vieja prensa partidista orientada a los militantes, ni aquellas centradas en debates ideológicos y excesivamente teóricos, sino que disputar por medio de los mecanismos de mercado consolidados por la dictadura, las realidades y los sentidos de significación, que permitieran la erosión del apoyo con el que contaba el régimen de facto.

Para Bastías el surgimiento de la prensa política de oposición fue un procesocrucialeneldesarrollodelasociedadcivilendictadura, porquerepresentó la "ampliación de las interacciones públicamente mediadas que permitieron la generalización de los contenidos emancipatorios y democratizantes que existían en las redes organizacionales hacia la sociedad en su conjunto" (2014: 149). Fueron las revistas y diarios las que pusieron en circulación contenidos creados en los Centros Académicos Independientes y en el exilio, todos caracterizados por el anhelo de libertad y lucha por los Derechos Humanos. 
La primera revista de oposición que surge fue APSI (Agencia Publicitaria de Servicios Informativos), iniciativa de un grupo proveniente del clausurado Comité Pro Paz en 1975. A través del financiamiento que entregaron las Agencias de Cooperación Entraide Fraternité y Novib, en 1976 salió a la luz el proyecto de "una revista de actualidad internacional" cuya máxima era "paliar el aislamiento internacional en el cual el régimen pinochetista mantenía al país" (Moyano, 2009). La revista nació gracias al uso de un tecnicismo legal que permitió la existencia de medios de comunicación independientes que dieran cuenta "única y exclusivamente" de temas internacionales. Así entre 1976 y 1979 APSI publicó 58 números que cumplieron con esta normativa. En julio de 1979, en la edición 59 aparece por primera vez un tema nacional: la discusión respecto del próximo plebiscito que fijaría una nueva Constitución para Chile.

Durante su primer período (1976-1979), la revista se financió con recursos internacionales y por medio de suscripciones en Chile y en el extranjero. Circulaba en formato boletín, con un promedio de 12 páginas y periodicidad quincenal. Su público lector estaba constituido por personas "de cierto nivel cultural, que constantemente no quedan satisfechos con las informaciones que se publican en la prensa nacional"7. APSI indicaba que su enfoque se fundamentaba en "una sólida base académica para interpretar la realidad nacional". ${ }^{8}$

A partir de 1978 la revista da cuenta de un proceso de restructuración, dotándose de un director, editor internacional, editor cultural, centro de documentación y representante legal. En 1980 se incorporaron nuevos "colaboradores" tanto nacionales como extranjeros, con autoría expresa. En este mismo año la revista incorpora, por primera vez y de manera sistemática la promoción de suscripciones de otras revistas nacionales e internacionales. Por medio de avisaje publicitario se promocionaron las revistas Hoy, Turismo y Recreación, Qué hacemos, La Bicicleta y Cuadernos del Tercer

7 Comentario de Revista Ercilla del 8 de septiembre de 1976, usado como promoción por APSI, No18 (1977) 9.

8 APSI, Nº18 (1977) 19. 
Mundo, editada en México. En conjunto con ello, APSI participaba de una red de información constituida por Le Monde Diplomatique (Francia), Latin american, Movimiento (Brasil), Tempo (Mozambique) y Unidad (Costa Rica).

La incorporación de avisos publicitarios se consolida a partir de 1980, fecha en que también se crea el cargo de Gerente General. Tal como publicitaron en el N 134 de 1984, en conjunto con los "Editores de Revistas de Chile", APSI entendía la relación con un público lector conceptualizado como "consumidor importante" que por medio de una "comunicación directa, privada y tranquila", representa para "los avisadores una garantía que ningún otro medio puede ofrecerles"

El aumento de publicidad en la revista fue de la mano de la apertura política del régimen. Se promocionaron restaurantes, calefactores ambientales, teatros, editoriales, radios, Centros de Estudios y una particular guía de profesionales (médicos, abogados, imprentas y distribuidores) que pagaban por su aparición en la revista y eran participantes de las redes sociopolíticas de la publicación.

La segunda de las revistas de oposición nació en 1977 cuando un grupo de periodistas demócratas cristianos vinculado a la revista Ercilla, crítico de las nuevas políticas de información y publicación que habían levantado sus dueños Larraín y Cruzat, renunciaron al proyecto editorial para dar cuerpo a la Revista Hoy. Con aportes de fundaciones extranjeras vinculadas a la Iglesia Católica y gracias a la gestión del propio Cardenal Silva Henríquez, comienza su circulación el $1^{\circ}$ de junio de 1977.

En el mismo año se vende en quioscos la revista Academia, iniciativa de un grupo de periodistas vinculados a distintos grupos de oposición particularmente demócratas cristianos y sectores de la izquierda socialista- $\mathrm{y}$ la Academia de Humanismo Cristiano (AHC), con un tiraje inicial de 800 ejemplares. El lenguaje confrontacional y la abierta vinculación con reflexiones de oposición a la dictadura rompió su relación más directa con la jerarquía eclesiástica lo que provocó el cambió de nombre a Análisis, aunque siguió

9 APSI, No134 (1984) 20. 
patrocinada por el Cardenal Silva Henríquez, quien comprometió apoyo económico y técnico hasta 1983. Desde la primera etapa (1977-1983) estuvo marcada por una gestión que consideraba un consejo de administración, director, comité consultivo, coordinación, gerente, encargado de diseño y promoción, además de secretaria y representante legal. En 1979 se incorporó un consejo de redacción y un reportero gráfico.

La segunda de sus etapas está marcada por el fin del patrocinio de la $\mathrm{AHC}$, el aumento de suscripciones y la aparición de un presidente de directorio, ejercido por el académico y dirigente demócrata cristiano Fernando Castillo Velasco. El fin de su vinculación con la AHC coincide con el período de las primeras protestas y un sello abiertamente de oposición, cercano a la propuesta de unidad entre el centro político y la izquierda socialista renovada, que la llevó a ser la revista más perseguida, intervenida y censurada de las tres que hemos mencionado en este acápite.

Sus estrategias periodísticas no son muy distintas de las que sostuvo la revista APSI. Incluyeron publicidad y avisaje a librerías y editoriales vinculadas a la Iglesia Católica como Copromix (empresa autogestionada por sus trabajadores), financieras, laboratorios médicos, servicios básicos y la guía de profesionales que reitera varios de los nombres anunciados en la revista APSI. Durante la primera etapa predominaron extensos artículos con formato académico que incluyeron citas al final de los documentos con autoría expresa, así como largas entrevistas a expertos y políticos. A partir de 1983, la aparición de un mayor número de reportaje y la ampliación a temas culturales, incorporación de dibujos y caricaturas, expresa la ambición de extenderse a un público más amplio.

Por último, ya en la década de los 80 , en pleno desarrollo de las jornadas de protesta social y vinculada a la socialdemocracia europea y latinoamericana nace la revista Cauce, principal órgano del socialismo en proceso de renovación, bajo la representación legal del abogado Gonzalo Figueroa Yáñez. El directorio de la revista estuvo compuesto por Figueroa, su director Carlos Neely Ivanovic y el editor Edwin Harrington. Bien entrada la década de 1980 José Joaquín Brunner y Ángel Flisfisch, connotados socialistas, se vuelven 
colaboradores activos de la publicación. A fines de 1988 Ángel Flisfisch se convierte en el director y representante legal de la revista.

Al igual que la revista APSI, Cauce se financió con aportes basados en suscripciones y la incorporación de publicidad que daba cuenta de las redes de izquierda. Restaurantes, librerías, radio Cooperativa y otras revistas culturales constituyen pistas de los lectores y también de los espacios frecuentados en una cultura política que se había transformado profundamente en sus conceptos y símbolos de identidad. Cauce afirmaba desde su primer número que "somos contrarios a los dogmas, a los fetichismos ideológicos de cualquier bandería y a la intolerancia de cualquier pretexto", ${ }^{10}$ rechazando abiertamente las formas comunicativas de la izquierda sesentista y abrazando la construcción de sentidos comunes democráticos, críticos pero no sectarios.

Por último, cabe indicar que los diarios tuvieron una aparición tardía. En 1984 nace el Fortín Mapocho y hacia fines de la década el diario La Época, fuertemente influenciado por el modelo de comunicaciones y estrategias periodísticas que disponía El País de España y La Reppublica de Italia, dispositivos fundamentales en la renovación de la izquierda socialista.

Al igual que varias de las publicaciones de la izquierda durante los años 50 y 70, la prensa de oposición tuvo que lidiar con las fuentes de financiamiento, incluir publicidad, mantener un lenguaje neutro, informativo y a la vez ser capaz de disputar los sentidos comunes y símbolos que había instalado la dictadura. El principal objetivo fue validar el espacio político, legitimar la disputa política e instalar en la escena pública a los principales líderes de la oposición nacional. Pero, las formas de validación del espacio político y legitimación de la actividad política expresaron características diferenciadas entre diarios y revistas, siendo estas últimas las más importantes para la difusión de los debates de la izquierda, principalmente socialista. Mientras Análisis y Cauce tenían un carácter más intelectual, con profundidad en los debates y con alta presencia de columnistas, APSI y Hoy optaron por

10 Cauce, $\mathrm{N}^{\circ} 1$, página editorial (1983) 
reportajes y entrevistas de temas contingentes nacionales e internacionales.

En este nuevo escenario, cabe consignar la desaparición de la prensa política de masas comunista, tan relevante en el período anterior y una presencia muy significativa de la izquierda socialista que recogía el concepto de hegemonía de Gramsci, participando de nuevas concepciones de la política.

Legitimar la política y construir un sentido común democrático

Quienes asumieron la elaboración y conducción de las nuevas revistas de oposición, fueron mayoritariamente militantes $-\mathrm{O}$ ex militantesvinculados al Partido Socialista, MAPU, MAPU-OC, Izquierda Cristiana y en menor medida al MIR. Periodistas, publicistas, sociólogos e ingenieros fueron las experticias predominantes en la gestión económica y editorial de estas. Varios trabajaron en Centros Académicos Independientes y en ONG, donde la comunicación social y política se había convertido en un campo importante de reflexión y debate.

La relegitimación de la política implicaba volver a valorizar el debate, disponer de actores cuyas voces fuesen identificadas como hablantes creíbles, portadores de saberes y cuyos lenguajes excluyen la descalificación y la radicalización asociada al período de la UP. La información debía combinarse con denuncia, construcción de una cultura de derechos humanos, revalorización de la democracia, crítica a los totalitarismos de cualquier signo y contribuir a la reconciliación nacional. Era necesario validar a la oposición como actor político, pero también reducir el campo de la política a un espacio técnico y profesional, de manera que los conflictos pudieran ser enunciados para ser resueltos y no como aporías o rupturas insalvables. Como se aprecia en el Cuadro 1, las revistas diseñaron estrategias periodísticas a partir de nuevas secciones y contenidos que sirvieron de plataformas de legitimación y socialización de los actores políticos, desdibujándose las conexiones con el pasado pre Golpe de Estado. De un total de 1322 menciones de líderes políticos que aparecen en las revistas entre 1979 y 1989, el 70\% corresponde a líderes políticos presentados como actores contingentes, sin vínculo (resaltado) con el pasado político inmediato. 
Cuadro 1: Presentación de los líderes políticos de oposición en las revistas política APSI, Análisis, Cauce y Hoy

\begin{tabular}{|c|c|c|c|c|}
\hline \multirow[b]{2}{*}{ Intelectual } & \multicolumn{3}{|c|}{ CATEGORIA DE PRESENTACIÓN } & \multirow[b]{2}{*}{ Total } \\
\hline & $\begin{array}{l}\text { Trayectoria } \\
\text { política pasada }\end{array}$ & $\begin{array}{l}\text { Líder político } \\
\text { presente }\end{array}$ & & \\
\hline 1979 & 5 & 1 & 0 & 6 \\
\hline 1980 & 37 & 11 & 3 & 51 \\
\hline 1981 & 36 & 2 & 3 & 41 \\
\hline 1982 & 18 & 0 & 3 & 21 \\
\hline 1983 & 34 & 12 & 57 & 103 \\
\hline 1984 & 28 & 16 & 135 & 179 \\
\hline 1985 & 24 & 7 & 56 & 87 \\
\hline 1986 & 36 & 4 & 129 & 169 \\
\hline 1987 & 31 & 17 & 184 & 232 \\
\hline 1988 & 22 & 12 & 151 & 185 \\
\hline 1989 & 35 & 9 & 204 & 248 \\
\hline Total & 306 & 91 & 925 & 1322 \\
\hline
\end{tabular}

Fuente: Elaboración propia en base a número de líderes mencionados según etiqueta de presentación en cada una de las publicaciones.

Obviamente, los contenidos de estas directrices no obedecían solo a una estrategia de oposición en el corto plazo, sino que eran expresión de una profunda transformación en la izquierda que había asumido una vocación democrática y que había abandonado el lenguaje marxista clásico, tanto como la creencia en que el socialismo debía ser un tipo particular de sociedad.

Con todo, es posible distinguir en las revistas de oposición dos períodos en el proceso de legitimación de la política y de redefinición de lo político. Uno que se extiende entre 1979 y 1983 que se caracteriza por la preeminencia de un debate "político tecnocrático crítico" con relevancia de "los intelectuales" vinculados a los Centros Académicos Independientes y ONG; y otro que se extiende entre 1983 y 1989, donde predomina el "político profesional 
propositivo", que combina trayectorias políticas y académicas, tanto en Chile como en el exilio, presentado como líder político en el "presente". (Ver Cuadro $1)$.

Las formas de comunicación estuvieron dirigidas a legitimar lo político a través de un lenguaje proveniente de la sociología y economía, mientras que el centro de las críticas apuntaron a las transformaciones económicas, los efectos sociales que habían generado las modernizaciones neoliberales, combinadas con la denuncia de la violación a los derechos humanos. Mediante el uso de técnicas sociométricas los intelectuales reflexionaron en torno a la transformación del sistema laboral, el desmantelamiento del modelo desarrollista, la refundación del modelo neoliberal primario exportador que sepultó lo que quedaba de la vieja clase trabajadora y que dio pie a la precarización laboral.

Entre 1979 y 1982, de un total de 222 textos contenidos en las revistas políticas de oposición, un 54\% se enunció como crítica al modelo de desarrollo, destacando un lenguaje que desde la economía política disputó sus límites y anticipó los efectos de la crisis económica. La mayoría de los líderes políticos fueron referenciados como expertos, resaltando su experiencia laboral presente o pasado y desdibujando su adscripción política.

Quienes enarbolaron dicho debate lo hicieron utilizando la "transitología" como fuente de saber, compartiendo conceptos y modelos analíticos disponibles en una amplia red de cientistas sociales que participaron del estudio de las "transiciones a la democracia". Las universidades itinerantes, como las denomina Lesgart (2002) fueron un espacio transnacional de enunciación que permitió la crítica a la izquierda y su actuación, desde un lenguaje académico que no abandonó lo normativo. APSI, Análisis y Cauce se convirtieron en fuentes de amplificación de ese debate, con el objetivo de participar de la construcción de los sentidos comunes que fundamentaran transiciones basadas en el consenso, acuerdos y construcción de mayorías políticas programáticas y no ideológicas. Las estrategias periodísticas combinaron este mensaje con la introducción de publicidad y marketing dirigidos a los sectores medios tradicionales y emergentes (Tironi, 2012). 
Posterior al ciclo de protestas que se extendió entre 1983-1985, la conformación de las alianzas políticas de oposición, la firma el Acuerdo Nacional y al fracaso de la Asamblea de la Civilidad en 1986, se produjeron las condiciones para que lo político se vinculara expresamente a la actividad partidaria, con fuerte presencia de líderes que lograron combinar el saber técnico con la adscripción a un sector de la oposición. Así, tal como muestra el cuadro anterior, entre 1983 y 1989 las revistas fueron un espacio que permitió legitimar el retorno de los partidos políticos, en conjunto con la validación de ciertos líderes cuya trayectoria y experticia los consolidó como líderes, con propuestas para avanzar en una transición a la democracia, cuyo itinerario se había fijado en la Constitución de 1980.

El espacio de enunciación de la política fue modificándose desde un mayor predominio de los artículos de opinión y editoriales a los reportajes y entrevistas. Se transita desde una actividad que se postula como clásicamente política: "opinar y reflexionar con autoría", a cuerpos de reportajes sobre las actividades y los que participan en ellas, delimitando el campo de lo que merecía ser cubierto por medio de la información. La actividad política se describe y se remite a otros, perdiendo notoriedad el ideólogo como autor.

Estos medios lograron una presencia significativa, superando la clandestinidad y entrando de lleno en el circuito de la industria masiva a partir de una forma de producción distinta a la que históricamente había caracterizado el campo mediático en el país, es decir, desvinculándose de la sujeción estricta a un partido y desarrollando lógicas de autogestión, que consistieron en dejar la administración y producción de recursos en manos de los equipos periodísticos. Esta característica, pese a no ser una iniciativa tan original, puesto que sus propuestas fueron discutidas desde el gobierno de Eduardo Frei Montalva en el marco del debate sobre el rol que le correspondía al Estado y a los medios de comunicación para asegurar un sistema de comunicación democrático y pluralista (Rivera, 2017), le permitió a las revistas políticas de izquierda operar de manera independiente en relación a los contenidos que publicaban, ya que eran los propios periodistas quienes, de manera consensuada, definían las estrategias a seguir. Sin embargo, este 
modelo tenía su piedra de tope en materia económica, puesto que los medios siguieron supeditados tanto a los financiamientos externos - principalmente internacionales-, como a tecnologías muy precarias, por lo que se vieron en la imposibilidad de adaptarse al mercado comunicacional una vez iniciada la transición en $1990 .{ }^{11}$

\section{CONCLUSIÓN}

A partir de este recorrido por el análisis de las estrategias periodísticas que desplegó la izquierda chilena por cuatro décadas, queda en evidencia la complejidad del juego político que se dio a su interior, el que no solo se limitó a los cambios en las relaciones entre proyecto ideológico e industria periodística, sino también a los contenidos sustantivos que dicha relación implicó en la definición y posición de la manera de intervenir en la construcción de la opinión pública, la disputa de los sentidos comunes y las formas de hacer política: una dialéctica entre el partido, los periodistas y la sociedad.

La diversidad de dispositivos periodísticos de izquierda — tanto de masas como militantes - antes del golpe de Estado del 73, donde destaca el PCCh, se modifica sustancialmente en el proceso de reconstrucción de la oposición democrática durante la dictadura militar.

En el nuevo escenario pos 73, las revistas que se erigieron como publicaciones disidentes desde 1976, tuvieron por objetivo relegitimar la actividad política, instalar liderazgos en la opinión pública y fomentar un debate tecnocrático, con el fin de introducir una forma de discusión centrada en el "saber hacer" y no en dogmas o, en futuros con transformaciones radicales, develando a su vez el giro teórico que se estaba desarrollando al interior de ciertos sectores de izquierda a las que estaban vinculados; es decir, aquella que abogaba por la renovación socialista, proponiendo el consenso y la negociación como elementos centrales para un retorno a la democracia.

11 Las revistas en cuestión permanecieron en el mercado mediático hasta entrada la transición. La primera en cerrar fue Solidaridad en 1990, luego el diario Fortín Mapocho en 1991, Análisis en 1993, APSI en 1995, el diario La Época en 1997 y Hoy en 1998. La situación para las radio emisoras fue diferente. 
La legitimación de la actividad política, demonizada por la dictadura militar, pudo ser restituida gracias al peso de una tradición del hacer político, en donde siguió liderando la prensa como un dispositivo clave para la construcción de opinión pública. Las revistas políticas, en las que transitaron los políticos y expertos, contribuyeron a estrechar el campo de lo político, redefiniendo los tipos de prácticas y actores que podían participar de una política democrática. La distancia entre lo social y lo político quedó consignada como el ideal de una sociedad estable y con capacidad para resolver conflictos: 'nunca más aporías ni teorías teleológicas'.

La desaparición de las revistas políticas que surgieron en la dictadura ocurrió, por una parte, como el resultado de una dependencia excesiva de fuentes de financiamiento externas, que no incentivaron la construcción de mejores estrategias empresariales destinadas a su autofinanciamiento en el mercado. Según Guillermo Sunkel, a esto se sumó la discriminación efectuada por empresas y agencias publicitarias comprometidas ideológicamente con "la prensa oficialista" (Sunkel y Geoffroy, 2001: 32). Por otra parte, las políticas de comunicaciones asumidas por los gobiernos de la Concertación, sustentadas en la idea de que "la mejor política es no tener política", dejó el campo de la comunicación abierto a los agentes del mercado sin una mínima regulación del mismo (Sunkel y Geoffroy, 2001) pues se pensó que era una forma de asegurar la representación ampliada y pluralista. No obstante, Giselle Munizaga asegura que el gran problema de esta reflexión fue pensar esta política cultural en un escenario ideal, ignorando que en el mercado se producen múltiples distorsiones y predominan procesos de competencia imperfectos (2004: 118).

A esto se agregó el proceso de desgaste que experimentaron estas revistas. La reconstitución de la democracia alteró los procesos de producción informativa y las conductas periodísticas, que no fueron capaces de insertarse en los procesos de cambios políticos y sociales que traía consigo la transición. Por una parte, la prensa política de izquierda experimentó una crisis en los contenidos, producto de la reiteración de ciertos temas que, más allá de su legitimidad, como en el caso de los derechos humanos, perdieron impacto en la sociedad. A esto se sumó una crisis en los lenguajes, puesto que si bien este 
tipo de prensa inauguró un discurso antiautoritario eficaz, en la transición a la democracia, cambió sus señas de identidad y perdió su espacio de creación (Reyes Matta, 1989). La reducción del campo político y la tecnocratización de la política, en conjunto con la validación de los partidos como agentes de la democratización, impactó en las propias configuraciones del sentido de las revistas políticas. Además, las transformaciones que sufrieron las grandes empresas periodísticas convencionales (Reyes Matta, 1989), mostraron una mayor flexibilidad para alterar sus modos de producción a partir de la incorporación de nuevas tecnologías, reorientar a los equipos de redacción, y reformular sus agendas recuperando muchos de los temas que fueron propios de la prensa de oposición, quedando la izquierda socialista sin la primacía de los contenidos que le habían permitido su instalación en el campo de las comunicaciones.

\section{REFERENCIAS}

Álvarez, R. (2011). Arriba los pobres del mundo. Cultura e identidad politica del partido Comunista entre democracia y dictadura, 1965-1990. Santiago: LOM Ediciones.

Bastías, M. (2014). Sociedad civil en dictadura, 1973-1989. Santiago: Editorial Alberto Hurtado.

Bergot, S. (2004). "Quimantú: editorial del Estado durante la Unidad Popular chilena (1970-1973)”, Pensamiento Crítico, n 4 (noviembre) 1-24.

Bourdieu, P. (2005). "The political field, the social science, and the journalistic field", en Bourdieu and The Journalistic Field. Gran Bretaña: Polity Press

Casero-ripollés, A. (2004). "Medios de comunicación y actores políticos en situaciones de crisis: la producción negociada de la realidad política", en Revista de Estudios de Comunicación. n ${ }^{\circ}$ 17, 143 -164.

. (2006). "La crisis política como fenómeno comunicativo: la emergencia del "caso crítico", Sphera Publica. Revista de Ciencias Sociales y de la Comunicación, $\mathrm{n}^{\circ}$ 6, 179-192. 
Contardo, S. (1985). “Abuso de publicidad, Ley y Derecho", en Comunicación $y$ Medios, $\mathrm{n}^{\circ}$ 5, 21-38.

Couyoumdjian, R. (1998). "La Hora", 1935-1951. Desarrollo Institucional de un Diario Político", Historia, n³1, 5-56.

Donoso, K. (2013). "El apagón cultural en Chile: políticas culturales y censura en la dictadura de Pinochet, 1973-1988”, Outros tempos, n¹6, 104129.

Drake, P. (1992). Socialismo y Populismo. Chile 1936-1973. Valparaíso: Ediciones Universitarias.

Faure, A. (2017). “¿Contribuyeron los medios de comunicación al golpe de Estado? Otra historia del periodismo durante la Unidad Popular (19701973)", Izquierdas, n 35 (septiembre), 71-97.

Garrido, P. (2017). Clasistas, antiimperialistas y revolucionarios. El Partido Socialista de Chile y la trayectoria político ideológica del Frente de Trabajadores, 1953-1967, Tesis para optar al grado de Magíster en Historia de la Universidad de Santiago de Chile.

Kircher, M. (2005). "La prensa escrita: actor social y político, espacio de producción cultural y fuente de información", Revista Historia, ${ }^{\circ} 10$, 115-121.

Le, E. (2010). Editorials and the Power of Media. Interweaving of sociocultural identities. Amsterdam/Philadelphia: John Benjamins Publishing Company.

Lechner, N. (2006). Obras escogidas, Tomo 1. Santiago: LOM Ediciones.

Lesgart, C. (2002). "Usos de la transición a la democracia. Ensayos, ciencia y política en la década del ochenta”. Estudios Sociales. n 22-23, 163185.

López, H. (2014). Un Sueño llamado Quimantú. Santiago: CEIBO.

Mattelart, A. (1970). "Estructura del poder informativo y dependencia", Cuadernos de las Realidad Nacional, n³, 37 - 73. 
Moyano, C. (2009). "Los líderes de la izquierda. Configuración de las elites en el imaginario político chileno dictatorial y el rol de las revistas políticas de oposición, 1973-1989”, Bicentenario, Revista de Historia de Chile y América, vol.8, n $1,55-86$.

- (2016). "La intelectualidad de izquierda renovada en Chile durante los 80", Historia, vol.2, n²3, 1-31.

Munizaga, G. (1984). Revistas y Espacios comunicativos. Santiago: CENECA. . (2004). "Las políticas comunicacionales de la Transición". En RICHARD, N. (2004). Utopia(s).1973-2003. Revisar el pasado, criticar el presente, imaginar el futuro. Santiago: Editorial Universidad Arcis.

Ossandón, C; Santa Cruz. E. (2005). El Estallido de las Formas. Chile en los albores de la Cultura de Masas. Santiago: LOM Ediciones.

Portales, D. (1981). Poder económico y libertad de expresión. La industria de la comunicación chilena en la democracia y el autoritarismo. México: Editorial Nueva Imagen.

Reyes Matta, F. (1989). "Periodismo en América Latina. Transiciones y Nuevas Tecnologías”. En DURÁN, C.; REYES MATTA, f.; RUIZ, C. La prensa del autoritarismo a la libertad, Santiago: CERC-ILET.

Riquelme, A. (1984). El debate ideológico acerca de la comunicación de masas en Chile: 1958-1973. Santiago: CENECA.

- (1986). Trabajadores y pobladores en el discurso de la prensa sectorial popular: Chile, 1958-1973. Santiago: CENECA.

Rinke, S. (2002). Cultura de Masas. Reforma y Nacionalismo en Chile, 1910 a 1931. Santiago: DIBAM.

Rivera, C. (2015). "Diálogos y reflexiones sobre las comunicaciones en la Unidad Popular. Chile, 1970-1973”. Historia y Comunicación Social, $n^{\circ} 20(2), 345-367$.

. (2017). "Prensa y Política. El Poder de la Construcción de la Realidad. Chile, siglo XIX-XX", Capítulo VII. En JAKSIC, I.; OSSA, J. (eds.) (2017) Historia Politica de Chile, 1810-2010. México: Fondo de Cultura Económica. 
Santa Cruz, E. (1996). Modelos y estrategias de la prensa escrita en procesos de modernización: Chile siglo XX. Santiago: Universidad Arcis/Centro de Investigaciones Sociales/ Documentos de trabajo.

- (2015). Prensa y Sociedad en Chile, Siglo XX. Santiago: Editorial Universitaria.

Sunkel, G. (1985). Razón y Pasión en la Prensa Popular. Un estudio sobre la cultura popular, cultura de masas y cultura política. Santiago: ILET.

Sunkel, G; Geoffroy, E. (2001). Concentración económica de los Medios de Comunicación. Santiago: LOM Ediciones.

Tironi, E. (2012). Sin miedo, sin odio, sin violencia. Una historia personal del NO. Santiago: Editorial Ariel.

Tuchman, G. (1983). La producción de la noticia. Barcelona: Gustavo Gili. 